\title{
Forms of resistance in people with severe and profound intellectual disabilities
}

1. Clare Nicholson (clare.nicholson@stmarys.ac.uk)*

2. W. Mick L. Finlay (mick.finlay@anglia.ac.uk)**

Orcid ID: 0000-0002-9351-0151

3. Steven Stagg (Steven.stagg@anglia.ac.uk)**

* Faculty of Sports, Health and Applied Science, St Mary's University, Twickenham, Waldegrave Road, Twickenham, LondonTW1 4SX

**School of Psychology and Sport Science, Anglia Ruskin University, East Road, Cambridge, CB1 1PT

\section{CRedIT statement}

Clare Nicholson: conceptualization (lead); investigation (lead) writing - original draft (lead); formal analysis (lead). Mick Finlay: conceptualization (supporting); review and editing (lead); formal analysis (supporting). Stephen Stagg: conceptualization (supporting); formal analysis (supporting); review and editing (supporting).

\section{Data availability statement}

Research data are not shared. Participant confidentiality could not be protected if video data are shared because individuals could be visually identified.

NOTE. THIS ARTICLE IS UNDER EMBARGO AND NOT FOR DISTRIBUTION. ACCEPTED BY SOCIOLOGY OF HEALTH AND ILLNESS 6/1/21 


\title{
Forms of Resistance in People with Severe and Profound Intellectual Disabilities
}

\author{
Abstract \\ Government policy in the UK emphasises that people with intellectual disabilities should \\ have the opportunity to make choices and exert control over their own lives as much as \\ possible. The ability of a person to resist activities and offers is therefore important, \\ particularly for people with severe and profound intellectual disabilities, who are likely to \\ have language impairments and need to communicate their choices non-verbally. Video and \\ ethnographic data were collected from two services for people with severe and profound \\ intellectual disabilities. Examples of resistance by people with severe and profound \\ intellectual disabilities and responses to that resistance by support workers, were collected \\ and examined using conversation analysis and ethnographic description. A range of non- \\ verbal resistance behaviours are described, and the difficulty for support workers in \\ identifying resistance when behaviour is ambiguous is discussed. The importance of \\ understanding these behaviours as examples of decision-making is stressed.
}

\section{Key words}

Resistance; severe intellectual disabilities; profound intellectual disabilities; empowerment; self-determination; conversation analysis; interaction; social care; non-verbal; communication; decision-making; person-centred; video; qualitative 


\section{Forms of Resistance in People with Severe and Profound Intellectual Disabilities}

The United Nations Convention for the Rights of Persons with Disabilities (2006) has as a guiding principle the respect for 'individual autonomy including the freedom to make one's own choices'. Further, UK Government policy emphasises that people with intellectual disabilities should have as much opportunity to make choices and have control over their lives as possible (Department of Health, 2001, 2009 a\&b, 2015). Although these documents set out principles and objectives, they lack detail about how to encourage choice-making in practice, and tend to refer to bigger life choices such as where to live and who has control of finances. However, the smaller, more frequent everyday decisions, such as who to sit next to in a room, what to eat, and which activities to take part in, are often overlooked (Antaki, Finlay \& Walton, 2009). For a person to act in a self-determined manner, they need not only to initiate activities and choose from different options, but also to communicate to others when they do not want to participate in something (Wehmeyer \& Field, 2007). This article reports a qualitative examination of how people with severe and profound intellectual disabilities (SPID) resist activities proposed in care settings, and how support workers respond.

Muntigl (2013) defines resistance "as a form of non-compliance (e.g. opposition or avoidance)" (p.18). For the purposes of this paper, we define it operationally as behaviour that signals unreadiness, inability or unwillingness to participate in an activity, in whole or part, or which signals a person's preference for an alternative course of action. It can be difficult for a person with SPID to show their objection to activities and situations. People with this label need support with everyday tasks and have limited symbolic communication abilities (American Psychiatric Association, APA, 2013), which means that the meaning of their behaviours may often be ambiguous. Various guidelines (e.g. Nind \& Hewitt, 2001; 2012; Ware 2003) which advise on interacting with people with severe intellectual disabilities 
recommend that communication partners should stop an activity when a person with severe intellectual disabilities disengages from it. However, when supporters are faced with ambiguous behaviour, it can be difficult to decide when it is appropriate to pursue an activity and when it is better abandoned (Finlay, Antaki, Walton \& Stribling, 2008a).

Ambiguity can arise for a number of reasons. It might be unclear whether the resistance is permanent (the person never wants to do the activity) or temporary (the person doesn't want to do it right now), whether it is directed at a part of the activity or the whole, or whether it is an act of playfulness or real rejection. The supporter also might not know if the resistance is because of the activity itself, the environment (e.g. too busy, noisy, cold or hot, too many distractions), a dislike for the supporter, fear, anxiety and so on. Apparent passive resistance (e.g. immobility and disengagement) may occur because the person is drowsy, in pain, distracted, unsure of how to respond, experiencing a seizure, or incapable of carrying out the required motor functions, rather than because they dislike the activity.

It is important to study how people with SPID resist activities in everyday settings for a number of reasons. First, it helps us understand the variety and range of communicative behaviours used by people who lack symbolic language skills. Second, it encourages us to take the small acts of self-determination in a person's life seriously, as a fundamental site of empowerment and choice, and allows us to see everyday situations of disempowerment more clearly. Finally, it raises a question about how DSM-5 describes people with SPID as unable to "make responsible decisions regarding well-being of self or others" (p.36, APA, 2013).

A few studies have examined how people with SPID demonstrate resistance. Finlay, Antaki and Walton (2008b) examined how people with severe intellectual disabilities resisted being weighed by not putting their feet on or moving away from the weighing scales, tensing their bodies, making vocalisations that supporters understood to mean 'no', facing the wall, dropping to the floor, and singing a nursery rhyme. In the examples presented in that paper, 
despite clear behaviours which were acknowledged by staff as meaning the person did not want to be weighed, the staff continued to try to persuade them to participate. Finlay et al (2008a) also describe two extended examples in which it was ambiguous whether a person with SPID, by continually dropping an item, was engaging with informal games initiated by care staff or trying to resist them. Further research relating to how people with SPID resist activities suggests that people may feign or go to sleep to avoid activities. For example, Porter, Ouvry, Morgan and Downs (2001) interviewed friends and family of a man called Peter, who reported that he chose not to join in an activity by going to sleep.

\section{Studies of resistance in the general population}

Conversation analysis (CA) is a method which allows for a fine-grained examination of both verbal and non-verbal behaviours (for an overview of CA methodology in analysing interactions involving people with limited communicative resources see Sidnell and Stivers,

2014). Conversation analysts have studied how people show resistance in a variety of settings including political interviews (Heritage, 2003), complaints (Mandelbaum, 1991), academic supervision (Vehvilainen, 2008), workplaces (Heath, 1986), classrooms (Monzoni, Duncan, Grünewald, \& Reuber, 2011), playgrounds (Lytra, 2007), police interviews (Forrester \& Ramsden, 2000), family mealtimes (Kent, 2011) and helpline calls (Kitzinger, 2000). Research has also examined clinical populations and/or healthcare interactions. For example, MacMartin (2008) gives examples of clients resisting questions from psychotherapists, while Vehvilainen (2008) provides examples of patients resisting their doctor's institutional agendas. Other examples of patients resisting a physician's recommendations come from primary adult care (Costello \& Roberts, 2001), women giving birth (Jackson, Land \& Holmes, 2017), paediatrics (Stivers, 2006;2007), and oncology (Roberts, 1999). 
The various ways in which speakers demonstrate resistance verbally include rephrasing questions (Heritage, 2003), changing topic, providing accounts, presenting contrasting ideas and disagreement/denials (Widdicombe, 2017 as cited in Joyce, 2017). While most of this research has focused on talk, studies have also noted the non-verbal aspects of resistance, namely the use of silence, either as a non-response or a noticeably delayed response (e.g. Jackson et al., 2017; Kitzinger, 2000; Forrester \& Ramsden, 2000; Monzoni, 2011; Lytra, 2007), and body movement/posture (e.g. Heath, 1986) such as turning away and gaze withdrawal (e.g. Kidwell, 2006; Goodwin, 1981; Hoey, 2017). For example, Kidwell (2009) shows how young children resist adults' directives by averting their eye gaze.

This paper uses ethnography and CA to examine and describe the ways in which people with SPID use non-verbal behaviours to resist or delay activities that their support staff are attempting to engage them in. It builds on previous work by analysing how people with SPID resist a range of different activities to those in previous studies, as well as how support staff respond to these behaviours. Overall, it helps build a more comprehensive picture of the resources people with SPID use to exercise self-determination and choice.

\section{Methods}

Participants

Five participants with severe intellectual disabilities were videoed completing various everyday activities with 12 members of care staff. There were four male participants with severe intellectual disabilities and one female. Three of the participants with severe intellectual disabilities had no verbal abilities, one had a few phrases and the other had variable, but declining, verbal abilities with a significant delay. The mean age of participants with severe intellectual disabilities was 37.6 years, ranging from 31 to 48 . The care staff members included 4 females and 8 males. Their approximate number of years' experience varied from less than a year to $15+$ years. 
Setting

Participants were recruited at two research sites which both cater for people with intellectual disabilities (Langley and Daisy Way - names have been changed). Generally, the video footage was collected in these centres. Langley was a large day centre which provided services for approximately 40 people with intellectual disabilities. Daisy Way was a small residential centre for 7 adults with severe - profound intellectual disabilities.

Ethics

Ethical approval was granted by the UK Social Care Research Ethics Committee. Approval was also granted by the Research Governance Boards from the relevant local authorities. Pseudonyms have been used throughout this paper.

Compliance with the Mental Capacity Act

Each participant was assessed for mental capacity following the guidelines of the Mental Capacity Act, 2005, and related guidance published in 2007. XX completed these assessments alongside staff who knew the participants well. Materials were adapted to promote understanding by the participants with SPID. For example, information was presented using photographs as much as possible, and for Jenny, whose family was not English, the information was translated and presented by a fluent speaker. Information about the study was presented several times in a quiet environment and the person's understanding was assessed. As a result of this process, none of the participants were deemed to have the capacity to consent. In line with the Mental Capacity Act (2005), close family members were then contacted to act as consultees. They were provided with information about the research and asked to advise whether they believed the person with SPID would have consented if they had had the capacity to do so. For all the participants involved in the research, consultees advised that they believed the person would have agreed to participate in the research if they were able to so do. 
Procedure

Over approximately a year, one of the authors (XX) collected 40 hours of video recordings of everyday interactions in timetabled activity sessions such as physiotherapy, meals and art sessions. Ad hoc interviews were also conducted and ethnographic notes made. A subcorpus of the data showing possible resistance behaviours was made for the purpose of this analysis.

Alongside the examination of ethnographic notes, the video data were analysed using a bottom up conversational analysis approach. Transcriptions of samples of the video were completed using Jeffersonian style transcription (Jefferson, 2005; see Appendix A for details). Close attention was paid to the behaviours which formed the interactional turns, in particular to possible signs of resistance by participants with SPID, the response of support workers, and to the sequential organisation of the interactions.

\section{Analysis}

For the purpose of this paper, interactions in which there were possible signs of resistance on the part of the person with SPID were analysed. Two of the examples presented below are transcriptions of the interaction from video recordings (analysed using CA), the rest, for reasons of space, are summaries of interactions (from video), or descriptions of events and ad-hoc interviews recorded in the ethnographic notes. The examples were chosen to give a broad picture of both active and passive resistance, including a range of different behaviour types, and to illustrate some of the difficulties in understanding these types of behaviours.

Ideally, counting the instances of a particular behaviour or course of action within an interaction would demonstrate how regularly it occurred. However, the types of behaviours involved in resistance are often ambiguous, and it is also a rather arbitrary decision as to what counts as a single act of resistance, particularly when an interaction consists of multiple 
behaviours and modalities over a lengthy period in response to various different aspects of one overall activity. Furthermore, while lack of interactive behaviours can demonstrate resistance, this could also be due to an inability to understand what is required of an activity, an inability to complete it, or might be caused by the sedative effects of medication. For this reason, we chose to describe such behaviours in their contexts, examining how and when possible resistance was demonstrated by people with SPID, and how and when staff members treated those behaviours as resistance. It is important to note that although in this research there was variation in the level of resistance shown by the different participants, and indeed staff responses to it, examples of disengagement or resistance were frequent within both the video data and the ethnographic notes.

\section{Results}

Examples will be presented in three sections: 1) Lack of engagement with an activity; 2) Active resistance to an activity; 3) Resistance within an activity (active resistance or passive disengagement during an activity). All three can occur in isolation or together as part of the overall trajectory of an interaction.

1. Lack of engagement with an activity. The person demonstrates little or no engagement in an activity or interaction initiated by care staff.

Example 1. Jake rejecting a drink. In this example, we see how Jake rejects the offer of a drink through eye-shutting, gaze and lack of positive acceptance behaviours. Jake, has SPID and no verbal language. He uses a wheelchair and is considered to communicate using physical movements, facial expressions and vocalisations. Eric is a member of staff supporting Jake who has three years experience of working with people with SPID. Before this extract, Jake had placed his hand in his mouth 15 times in the recording. 
1 Jake ((leans slightly to the left of his wheelchair with his eyes open))

2 Eric ((walks over to Jake holding a bottle of squash in one hand and box of milkshake powder in the other))

4 Jake ((moves his head and looks up towards Eric's face for 0.5 seconds and then 5 moves his head so it is facing down towards the floor and closes his eyes))=

6 Eric JAKE

7 Jake $=(($ continues to face downwards clicking his tongue $))=$

$8 \quad$ Eric $\underline{\text { Jak:: }}: \mathrm{e}$

9 Jake $=(($ continues to face downwards clicking his tongue for $2 \mathrm{~s}))$

10 Eric $\left[{ }^{1}\right.$ hell:::o (.) I'm h[${ }^{2}$ ere $]$

$\left[{ }^{1}((\right.$ moves the bottle and boxes around in front of Jake's face $\left.))\right]$

12 Jake ${ }^{2}\left((\right.$ moves his head upwards from facing the floor $]\left[^{3}\right.$ opens his eyes and closes them again, keeping his head in an upright position))]

14 Eric

$\left[{ }^{3}\right.$ HELL: ::O (.)HELL:::O (1.8) pretend to be sleeping I don't mind]

Jake's behaviours in lines 4-5, where he lowers his head and shuts his eyes, appear to be a response to Eric's arrival in lines 2-3. Eric tries to engage Jake by use of his name (lines 6 and 8) and "hello" (line 10, 14 and 15), both of which are calls for attention. Although Jake does open his eyes in line 12-13, he closes them again immediately. Eric even verbalises his understanding of Jake's behaviours in line 15, where he says “pretend to be sleeping I don't mind". After this Eric spends a further 1 minute 20 seconds trying to elicit a choice of drink from Jake, before abandoning the activity. 
Example 2. Thomas ignoring a group of visitors. In this example, we see how a man with SPID uses non-response and closed eyes to resist engagement with others. Thomas's verbal abilities were declining, varied from day to day, and were significantly delayed. When he did speak, he often referred to topics that were discussed several minutes before. He could also smile and frown and often engaged in prolonged periods of eye-contact. His receptive language was considered the best of all the participants but was becoming more difficult to assess. In this example, Thomas was lying on his bed, something he did a lot due to ill health. XX had been in his bedroom that morning for about an hour, chatting and listening to music, and he was relatively alert. Then an advocacy group of seven people entered his room to see if he wanted to participate in a questionnaire. At this point, $\mathrm{XX}$ went into the room of another resident (B). Soon after, the advocacy group entered B's room, saying that Thomas was not completing the questionnaire as he was too tired. XX walked past Thomas's room a few minutes later. Thomas lay with his eyes closed. He then opened his eyes, saw XX and quickly shut his eyes again. XX said "Thomas?" and he opened his eyes and looked at her with a big smile. XX said that she wouldn't tell, and Thomas smiled more broadly at her. XX felt confident that Thomas had deliberately tried to "look tired" to avoid engagement with the advocacy group.

Example 3. Simon not engaging in painting. In this example, we see how Simon uses closed eyes, lack of movement, and failure to grip a painting tool to resist active engagement in an art activity. Simon is a man with SPID and no verbal communication. He has reduced vision and uses a wheelchair. During the study period, he frequently slapped his face repetitively, sometimes also scratching and gouging his skin, causing infections. 
This art session took place in the afternoon after lunch and personal care had been provided. Immediately before the session, Simon had been sitting in his chair lightly slapping his face. Simon is now sitting in his wheelchair wearing a painting apron. A canvas has been placed on a plastic tray attached to his wheelchair. Elvis, a support worker, is sitting to Simon's left at $90^{\circ}$ to Simon. Elvis has two years experience working with people with severe intellectual disabilities. He has placed a plastic painting spatula in Simon's hand and is moving it across the canvas. Simon either has his eyes closed or nearly closed and is facing away from Elvis. With the exception of his hand which is being manipulated by Elvis, he remains still with his eyes seemingly closed for the majority of the 15 minute art session.

For the first part of this interaction, Simon's behaviours really are minimal. He does not vocalise, change his position from facing away from Elvis, open his eyes, or seem to move his hand independently, all of which he is physically able to do. Elvis orients to Simon's lack of interactive behaviours several times, calling his name and saying "try doing that", "let's turn that around", "squeeze there" and "push that up". However, Elvis's behaviours do not elicit any response from Simon.

Elvis then slightly withdraws his hand-to-hand support from Simon, who lets go of the painting spatula, moves his hand to his face, and begins to rub it. It is unclear whether the spatula comes out of Simon's hand simply because he is not gripping it or he deliberately releases it. Elvis replaces the spatula and moves Simon's hand to begin painting again, and Simon's behaviours once again become minimal. Elvis comments that he believes Simon has actually fallen asleep, and ends the session. As soon as his hand is free, Simon rubs his face, an activity which he often does throughout the day. Thus, he is able to fulfil his own action agenda without overtly challenging Elvis (for example by pulling his hand away from the hand-to-hand support). 
In a multi-disciplinary meeting concerning Simon, the team acknowledged that Simon would deliberately withdraw from activities "pretending to sleep". This was considered a risk as he was then monitored less closely and might engage in self-harming behaviours. In this example, although Simon does not appear to actively participate in the painting while Elvis is holding his hand, he is not actively pursuing the potentially dangerous activity of rubbing, slapping or gouging himself. He also appears relaxed and shows no signs of distress. Whether Simon is resisting the activity or not is therefore unclear. While he resists the active involvement that would be necessary for a successful painting session, it may be that the touch from Elvis's hand, the sensory stimulation which is provided from the art equipment and paint, or even the undivided attention and talk directed at him by Elvis are intrinsically relaxing, soothing or enjoyable. Simon's behaviour is therefore ambiguous.

Example 4. Simon resists walking. In this example, Simon resists walking in a gait trainer by not moving his feet and facing the floor. Simon's gait trainer consists of a wheeled frame with a harness attached and is used to enable Simon to move around and improve his walking skills. This session takes place in the afternoon after lunch and personal care. Prior to the session, Simon had been sitting in his chair at the side of the main SPID room. He spent some time with his eyes closed and some time slapping his face. Simon is supported by Saheb, an agency care staff member who has been working with people with SPID for less than a year. He attaches Simon to the trainer and encourages him to walk. However, during the recording, Simon barely moves from his slouched position, with the vast majority of the session spent with his head facing the floor and his feet dragging along it. His eyes also appear to be closed. Throughout, Saheb pushes the gait trainer around, acknowledging Simon's minimal engagement with a range of verbal encouragements (e.g. "let's walk about"; “come on 
Simon, wakey wakey"). Indeed, early in the interaction, he says to XX, who is operating the camera, that he thinks Simon "does not want to walk today."

This example, like that of Simon in art, captures a theme that occurred several times in this research, namely staff members seemingly carrying out an activity "on behalf" of a person with severe intellectual disabilities. This regularly happened despite noticeable disengagement or resistance. Here, as in the painting activity, it is unclear if Simon wants the activity to stop or not. Since he does not actively resist, it is possible he may enjoy the interaction or the sensation of being pushed around. Again, his behaviour is ambiguous.

2. Active resistance to an activity. The person overtly resists an activity from the outset.

Example 5. Jake leaves the music group. In this example, we see how multiple acts of resistance by Jake using a mobility scooter are acknowledged and resisted by the support worker. Jake (from example 1) is being supported by Eric (also from example 1) in a music session. Although Jake usually uses a wheelchair, here he is using a 'scooter' (a block of foam with four small wheels attached to the bottom). When sitting on his scooter, Jake uses his feet to propel it unaided, increasing his ability to move around independently and allowing him to explore the environment as he wishes. The music session takes place in a large room in the day centre with about 20 people present. Percussion instruments have been given out to those who would like to use them. These weekly music groups, if joyous, are particularly noisy and not always tuneful.

At the start of the video, Jake is upstairs in a different room, where he is moving around freely. He seems happy: he vocalizes (sounds like 'ahh' and 'ohhh') and smiles widely. Eric then encourages him to go downstairs to the music group by placing his hand on the scooter and taking it down the corridor to where the lift is. Jake seems happy to go 
downstairs in the lift but appears to demonstrate his resistance to participating in the music session in a variety of ways. First, when he is in the corridor approaching the music room, still smiling and vocalising, he tries to continue down the corridor instead of going into the music room. However, Eric places his hands on Jake's shoulders and asks "Jake are you here for music group? This way for music group yea?" Eric then pushes the scooter into the room. Immediately after this, Jake "scoots" himself back out of the room. When Jake leaves the music room he is smiling widely and seemingly happily vocalising. Jake also stops and looks back towards Eric several times, then scoots along a corridor to the physio room which happens to be empty. He enters it followed by Eric, who sits down there. Jake's facial expressions become more neutral, but he continues to vocalize in a similar way and seems, at the very least, content. After 45 seconds of being in this room, Jake scoots himself towards the door and back down the corridor.

When Jake reaches the hallway near the music room, he stops and leans around the door slightly. Without speaking, Eric places his hands on the scooter, pushes Jake into the music room, and places his leg behind the scooter, apparently in an attempt to stop Jake moving back. Jake moves forward and then right, freeing himself from Eric's constraint. Eric starts to put his leg behind the scooter again but quickly retracts, perhaps influenced by the presence of the camera and researcher. Jake then turns himself around $180^{\circ}$ and once again scoots towards the door.

In the corridor, Jake heads for the lift. Once he reaches it, he vocalizes ('ERR $\underline{\mathrm{rr}} \downarrow$ rr'), reaches out his arm towards the lift, moves it from left to right three times (see Figure 1), and clicks his tongue. 


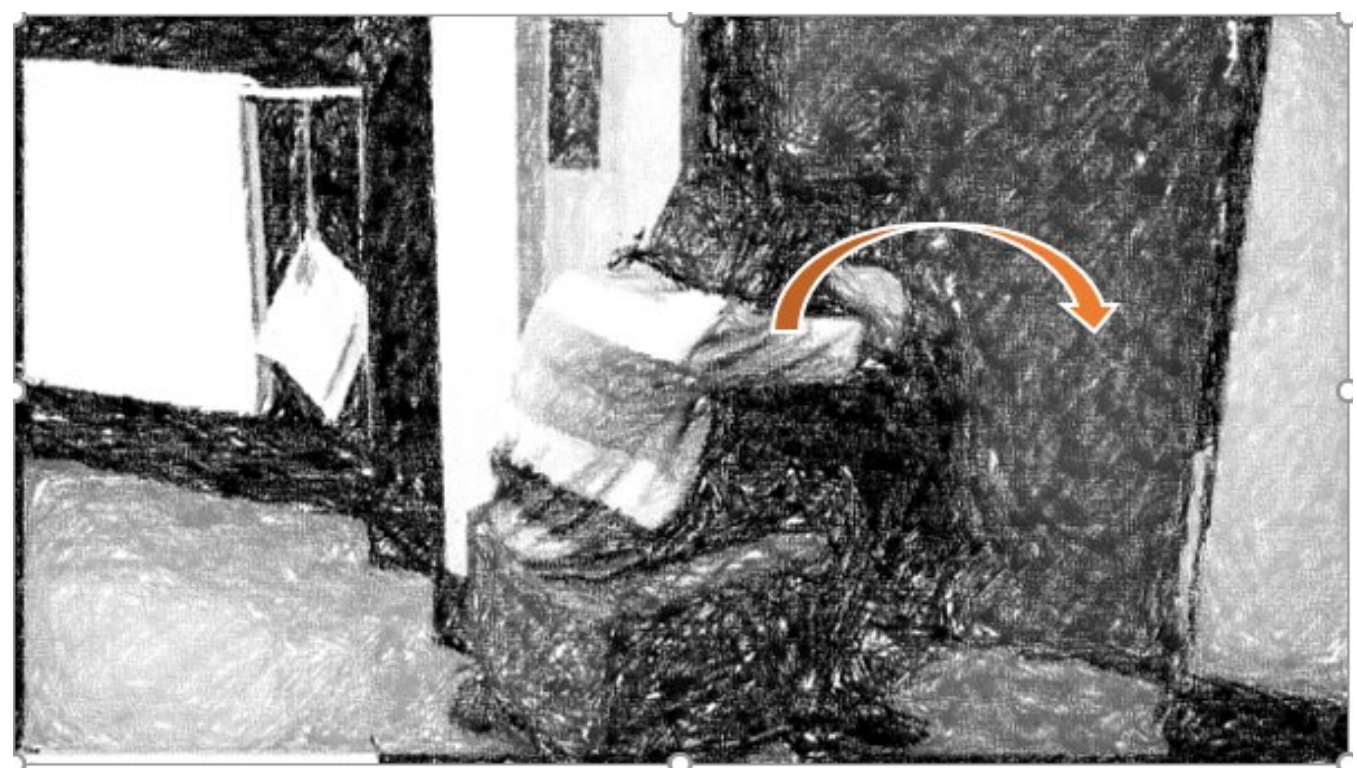

Figure 1. Jake reaches for the lift with arrow added to show his hand movement.

Eric comments "he wants to go upstairs", but does not enable him to do so. Jake makes a louder, deeper vocalization than before ('UR::HM!') and stamps his foot three times. He then continues to look at the lift, vocalising softly and occasionally banging his foot. Eric does not respond to these behaviours. After 1 minute and 20 seconds, Jake abandons the lift and begins to head toward the physio room again. Eric utters "Jake!", Jake stops and turns his head around, and then Eric says "Come on Jake, come with me" and once again pushes the scooter into the room with the music session.

There, Jake places his feet flat upon the floor, physically resisting Eric's push of the scooter further into the music room. Eric waits approximately 4 seconds, then begins to push again, positioning Jake near the other people. This time he keeps hold of the scooter with his hands making it impossible for Jake to move away.

Jake makes several further attempts to move his scooter, which Eric resists. Jake begins to go red in the face, and when Eric prevents him trying to push the scooter away using another chair, Jake thrashes his body, including his arms, which hit his head slightly. 
He then digs his fingernails into his hands, drawing blood. At this point the camera was turned off as required by the ethical protocol.

In this example, Jake demonstrates his resistance to joining the music session in a number of ways. He leaves the room three times. This is something he would not have been able to do had he not been in his scooter, and demonstrates how mobility aids can enable people with SPID to express choices. He also goes to the lift and acts in ways understood by both care staff and the researcher to signal that he would like to enter the lift. There is a stark contrast between Jake's wide smiles and high-pitched vocalisations which occur when he is able to move around freely and the lack of these behaviours when he is prevented from leaving the music group. Additionally, Jake physically resists the movement of his scooter by placing his feet flat on the floor. Finally, Jake thrashing and self-harming also resist the musical activity.

Eric does not appear to treat Jake's apparent choices as legitimate. Even when he describes Jake's behaviours as expressions of choice ("he wants to go in the lift"), he does not provide the required response to fulfil Jake's wishes (namely pushing the button for the lift). He continues to bring Jake back to the same room, even though Jake keeps leaving it, and he eventually forces Jake to stay in that room, which appears to cause Jake to become distressed. When XX asked Eric after the recording about why Jake left, he responded that "he wanted to go upstairs" and when asked why he kept bringing him back, Eric responded that he was "down to do music" suggesting "he shouldn't be on his scooter, that is a different activity". There was no logistical or safeguarding reason why Jake could not be on his scooter moving around the areas of the day centre, most of which were empty and which he could have been free to explore.

3. Resistance within an activity. The person actively resists or disengages during an activity. 
Example 6. Jenny resisting art activity. This extract illustrates some of the ambiguities in interpreting a person's resistance behaviours. It involves Jenny, a woman with SPID. Jenny regularly vocalises but does not appear to use words. She mainly uses facial expressions, gaze, posture and non-verbal vocalisations to communicate. This session took place in the afternoon. Immediately before it Jenny was in the main SPID room, alert, sometimes vocalising. Staff responded to her vocalisations as signs of her being happy. In this session, Jenny is in her wheelchair wearing an apron. A small table has been set up with painting equipment. Monty, a staff member with seven years experience is seated to her right. He is trying to ascertain her choice of paint colours by offering a verbal choice while physically presenting the paint pots. Jenny touches the purple paint pot (and Monty's hand holding it). Monty then suggests two more colours verbally, and physically presents a choice of three. After a delay, Jenny touches the white paint bottle and pulls it towards her. Then Monty provides a third choice of paint (red or green) both verbally and non-verbally. This section of the interaction is presented in the transcript below.

1 Monty _((holds the red and green paint bottles in front of Jenny)) shall we do one

5 Jenny ((reaches out and touches Monty just above the elbow, pushing it slightly 6

8 Monty None of them (.) so you just want purple and white

9 Jenny ((pushes Monty again and moves her hand back to her lap)) 
10 Monty A WISE CHOICE

11 Jenny ((Puts her arm in the air and looks towards it))

12 Monty ((places the paints back on the table))

13 Jenny ((pulls at the front of her apron))

14 Monty Woah woe woe

15 Jenny ((pulls her hand and arm inside the sleeve of the apron and starts flapping

16 her right arm so the loose end of the apron is moving side to side) $)=$

17 Jenny

18 Monty $=(($ starts to put his hand up the sleeve of the apron $))$

19 Gimmie that hand! (.) gimmie that hand back

20 Jenny ((starts pulling the body of the apron off herself $))=$

21 Monty ((looks at camera)) She doesn't wanna paint. You get the feeling she

22 doesn't want to paint ((smiles))

23 Jenny $=(($ continues to pull the apron off herself $))$

24 Monty You don't wanna paint (.) okay

In lines 5-7, Jenny gently pushes Monty's arm away, leaves her hand there and smiles. In line 8 , Monty shows he understands that Jenny is refusing the offer of an additional painting colour ("None of them?"). At line 11, Jenny begins to remove her apron. This continues and is more obvious in line 13. Monty then says "Woah", Jenny continues removing the apron (line 14), and Monty encourages her not to, both physically, by reaching for her arm in the sleeve, and verbally (18-20). After she continues removing the apron in line 21 , he directs his talk to the researcher, saying that she does not want to paint (line 22). Soon after the end of this transcript the activity is abandoned. 
Here we see a degree of ambiguity in Jenny's behaviour. It is unclear whether she changed her mind about painting during this interaction or whether some of her behaviours were misunderstood by Monty. For example, it is possible when she was reaching for the paints that she was just trying to touch Monty's hands and never had any interest in painting. Equally, she may have become warm in the apron, or not liked the fact the sleeves were slightly too long for her. In this case, she may have happily painted if other solutions were provided. Or it may be that she was being playful with the apron and looking for a lighthearted tussle, something she was understood by staff to do often with plastic aprons. While we cannot determine the reasons for her behaviour from the transcript, we can see how Monty comes to understand Jenny's removal of the apron as resistance to the art session in general. He only comes to this conclusion after suggesting that some signs of resistance (gently pushing his arm in lines 5-7) were resistance to $a$ part of the activity (selecting an additional colour) rather than to the activity as a whole (the art session per se).

After the art is abandoned, Jenny spends ten minutes sitting on the floor alone. Even if we could be sure that Jenny did not want to complete art, this does not necessarily mean she did not want to be social. However, this possibility is not explored by Monty.

Example 7. Jake leaves and then returns to music group. This example shows Jake demonstrating resistance to a different music group to that in example 5, this time by rocking in his wheelchair (he is not in his scooter in this example), thereby edging it forward. Baruk is supporting him in this morning music session. Before the session, Jake had been sitting near the door of the room for people with SPID. He was thought to enjoy sitting near doors, observing what was happening in the corridor and other rooms. Staff members came and greeted him as they arrived in the room. 
The group is listening to a Christmas $\mathrm{CD}$, singing along and playing percussion instruments. Baruk and Jake are sitting side by side. In the first three minutes of the video, Jake's behaviours are minimal. His eyes are closed, and his face is positioned towards the floor. He is slightly more alert in the $4^{\text {th }}$ minute, and Baruk gives him a maraca twice but each time he lets it falls to the floor. In the $5^{\text {th }}$ minute, Jake faces forwards with his eyes open. Up to this point, Jake is not engaging, but is also not carrying out alternative behaviours to resist the activity. This is another example of ambiguity: it is unclear if his lack of engagement at this point is resistance (e.g. to playing instruments), because he is listening to the music, or for some other reason.

When the group begin doing a new song, 'Silent Night', Baruk begins to shake the maracas in front of Jake's face and sing. At this point, Jake manages to move his chair slightly towards the door by rocking back and forth. Baruk continues to shake the maracas and sing loudly and out of tune, while Jake continues to rock and move his chair away from Baruk. Baruk finally responds to Jake's movement towards the door by offering to go for a walk in the corridor, which they then do. Soon after, they return to the session and stay for the remainder. Although Jake is not offered an instrument and does not engage in other ways such as clapping his hands or vocalising in time with the music, he is no longer clearly resisting the activity. He occasionally vocalises and 'jumps' in his chair, but the meaning behind these behaviours is not clear. This demonstrates how, although people with SPID may show signs of resistance during certain activities, the signs of resistance may become more active, disappear, or relate to a specific element of the interaction. For example, in this example it is possible that Jake's active resistance was specifically to Baruk's loud singing. After having a break, Jake did not repeat these signs of resistance. 
Example 8. Simon in physiotherapy session. This filmed interaction during a morning physiotherapy session includes several examples of Simon (from example 4) possibly resisting particular courses of action. It took place towards the end of the session. Simon is in the physio room with two other participants and three members of care staff. Simon had spent some of the session sitting still and slapping his face, which was discouraged by staff. At other times he used a ball and foam cylinder, seemingly happy making pant-like vocalisations. Monty (from example 6) has been assigned to support Simon. He encourages Simon to use a large red physio ball which is on a rubber mat. Simon rocks back and forward on it. He seems to enjoy it, moving quite quickly and vocalising. However, he then moves off the ball and sits on the mat, regularly slapping his face, a behaviour Simon often exhibits. He does this several times, actively crawling away from staff. This appears to demonstrate his resistance to continuing the activity of rocking on the ball. Monty encourages him to use the ball again and Simon returns to the activity, seemingly enjoying doing so, before again moving off it. Monty then encourages Simon to stand and supports him to move into that position. Simon bends his knees and leans towards the floor whilst standing. Monty takes this to indicate that Simon wants to stop the supported standing and return to sitting on the physio mat. Monty places a foam cylinder in front of Simon in an attempt to get him to use it. However, Simon clearly leans away from the foam cylinder.

Often, these signs of resistance occurred despite Simon seemingly enjoying the same physio activities before or after his resistance to them. It may be that he did not want to complete these activities for a prolonged period of time because of tiredness or boredom and simply wanted a break. We cannot know his intentions or motivations for certain, but his behaviours appear to demonstrate that at those moments he is not ready (i.e. attending, willing and able) to complete certain physio-related activities. Simon's resistance in this session differs from the examples discussed in the earlier section of no or minimal 
engagement, as Simon is disengaging intermittently, whilst at other times seemingly fully engaged in the same activities.

\section{Discussion}

The participants with SPID in this study appeared to signal resistance to an activity in a number of ways. In the full set of examples (only some of which are presented here), this included averted eye gaze, not gripping a tool, dropping or removing objects and clothes necessary for the task, body movements away from care staff and/or away from objects relating to the activity (including using an assistive mobility device), vocalisations, eye closing and seemingly feigning sleep, self-harming behaviours, pushing staff away, and stamping feet.

Some participants appeared to have more individualised ways to signal resistance. For example, Jake held his arm in the air and Simon would kick his legs, both vocalising at the same time. Other examples of resistance included trying to complete competing courses of action (such as slapping one's face when hands are needed for painting). A noticeable absence of behaviours necessary to complete an activity (such as immobile legs and feet when using a gait trainer or failure to grip and move a painting spatula during an art session) were also considered to be signs of disengagement and potential resistance.

Staff responses differed. In Example 5, despite Jake repeatedly demonstrating his unwillingness to participate in the music session, Eric did not treat this decision as legitimate, and Jake's behaviours escalated to face-slapping. In contrast, Monty quickly treated Jenny's potential resistance in example 6 as a clear sign that she wanted to terminate the activity, even before fully exploring any additional potential explanations.

Some of the behaviours described here have also been reported in the typical population. For example, general CA research shows that non-responses to previous turns may be a way of resisting the interaction (e.g. Monzoni et al., 2011; Kitzinger, 2000; Lytra, 
2007; Forrester \& Ramsden, 2000), as are certain non-verbal behaviours such as averted eyegaze (Kidwell, 2006; 2009). This demonstrates parallels between communication techniques used by people with SPID and the general population.

This research provides support to the observation that people with SPID may choose to be non-responsive by falling, or appearing to fall, asleep (e. g Porter et al., 2001). Indeed, staff referred to this explicitly several times in the dataset. In the examples presented here, participants were considerably more responsive immediately before or afterwards, suggesting that the non-responsiveness is unlikely to be caused solely by tiredness and/or drowsiness. Whether such responses are intentional or not, they still clearly signal that the person is not able, willing or ready to engage in the activity in question at that time. This should be recognized as a significant communicative resource used by members of this group to exercise choice in their daily lives.

Another important resource used to reject activities is the use of mobility aids (e.g. kneepads, gait trainer, specialist scooter) to allow a person to leave the site of the activity. Jake demonstrates his resistance to the musical activity by moving towards the door, and this is considerably easier for him when he is in his scooter as opposed to his wheelchair. Movement of specific body parts can also signal resistance. Examples of this include participants moving their heads away from staff members and/or stimuli, stamping their feet, lifting and stretching their arms, as well as pushing staff and/or objects away. For those unable to move their whole bodies away, this is a vital resource for expressing choice.

While some of the behaviours that actively demonstrate resistance were also seen in Finlay et al.'s (2008b) research (e.g. moving the body away, beginning an alternative, incompatible activity), this research advances our knowledge by demonstrating how resistance can relate to an activity as a whole, to individual elements within it, or can be a temporary state. This is one of the difficulties in interpreting resistance behaviours. For 
example, it is unclear whether, when Jenny removes her apron, she is resisting painting, is unhappy with the apron, or is simply being playful and wants the support worker to challenge her. Just because a person is not engaging in a particular part of an activity does not mean they are resisting the whole activity or the social interaction with the staff. In the example of Simon in the art session, just because he was not gripping the spatula or moving his hand does not mean he did not enjoy the touch of the supporter, their moving his hand, being talked to, or sharing a space with another person. One of the most difficult challenges faced by those supporting people with SPID is when to continue to encourage an activity and when to end it, particularly when the meaning of the behaviour is ambiguous (Finlay et al., 2008a). The examples presented suggest that at times the agendas of people with severe intellectual disability and staff members do not align. Svanelöv (2019) acknowledges that there are unequal power relations between people with intellectual disabilities and those staff who support them (see also Jingree, Finlay \& Antaki, 2006). He describes what he calls "a scheduled must", which is the idea that because an activity (such as eating) has been institutionally scheduled at a certain time, this is the time it must occur. While there may be practical reasons for this, such as arranging appropriate support for specific activities or exposing the person to 'therapeutic' activities, it limits the autonomy and freedom of choice of the person with intellectual disabilities. This phenomenon is seen in some of the examples in this paper. For example, when Eric was asked why he kept taking Jake back to the music session he explained that Jake was scheduled for music and should not have been on his scooter in the first place. Eric's rationale suggests that institutional schedules take precedence over the preference of the individual. Svanelöv (2019) suggests that institutional ideas of what is good for a person with disabilities are often imposed upon them in services, while Altermark (2017) points out that staff members tend to teach capabilities they think are necessary so that the person with intellectual disabilities to live as "normal" a life as possible 
(Björne, 2020; Hellzen, Haugenes \& Östby, 2018). However, this can leave little room for the person using the service to make decisions about how they spend their time. For example, despite Simon dragging his feet along the floor in extract 4, Saheb still pushes the gait trainer. Even though Saheb could be well-meaning, trying to encourage development of skills which may benefit Simon (i.e. walking), he is also exerting his position of authority and disempowering Simon. The risk of this sort of everyday disempowerment is greater the more a person is reliant on others to carry out everyday activities (Finlay, Walton \& Antaki, 2008).

The right of people with SPID to be able to make their own choices is central to both UK government white papers on services for people with SPID (Department of Health, 2001; 2009) and the UN Convention on the Rights of Persons with Disabilities (2006). In the convention, states are obliged to promote these rights in public services and refrain from engaging in practices that inhibit autonomy. However, the convention also requires states to promote participant and inclusion. While presumably one of the major reasons staff continue to promote or even complete activities on behalf of the people they support in this paper is to maximise participation in activities, this should not undermine the autonomy and freedom of the person with SPID. Institutional timetables need to be flexible enough to respect the everyday rights and choices of people with severe intellectual disabilities. Support staff therefore need to have the permission and ability to depart from fixed institutional agendas where appropriate, particularly when it would not cause detriment to the people using the service.

It is important to state that when we see support workers not responding to clear signs of resistance, we should not assume they are being deliberately inattentive or disrespectful. Some of the care staff in this paper also spent their days off visiting those they supported in hospital or used their own money to buy equipment to benefit them. Further training using real life examples such as those presented in this paper may be of some benefit, and 
encouraging staff to attend to resistance which is upgraded or repeated could be particularly beneficial.

We must acknowledge the position of the researchers in this analysis. We did not have direct access to the motivations or emotions of the participants, and therefore our interpretation of the participants' non-verbal behaviours were limited by our understandings as social psychologists as well as the understandings of the institutions and staff which we picked up through ethnographic engagement. We have tried to limit firm pronouncements on people's motivations and admit the ambiguity of their behaviours. Additionally, the presence of XX in the service may have influenced the actions of participants. For example, some staff members might have felt a stronger need to perform certain roles (e.g. maintainer of the timetable, teacher, coach) because they were being observed. A further limitation of this research is that the perceptions and intentions of the staff members were not comprehensively explored. For example, we cannot know from the video data whether the staff members felt compelled by institutional or co-worker expectations to engage in particular behaviours, or whether their actions are determined by more personal issues and values. The researchers planned to have sessions with the staff at the end of the project where they were given time and space to view their own footage and provide comments about it. However, before this could occur, one of the centres closed down while the other changed management and many of the staff left. Future research should aim to examine how staff perceive their own actions and if viewing video footage of interactions they were involved in leads to improved practice (Finlay, Antaki \& Walton, 2008c).

Finally, the examples in this research show that people with severe intellectual disabilities can and do make responsible decisions regarding their well-being, something that the DSM-5 claims they cannot do (APA, 2013; Nicholson, 2017). When we examine the details of everyday life, rather than just the big, more complex decisions (e.g. about diet, 
finance or living arrangements), we see people are able to remove themselves, or at least indicate they want to be removed, from situations which make them distressed, bored or unhappy.

\section{Data availability statement}

Research data are not shared. Participant confidentiality could not be protected if video data are shared because individuals could be visually identified.

\section{Acknowledgements}

We would like to thank Anglia Ruskin University who provided the funding for this project. We are also grateful to the editor and the anonymous reviewers whose useful comments which helped strengthen this paper. Finally, our unreserved thanks are given to the centres that accommodated this research and to all the participants involved.

\section{Address for correspondence}

Clare Nicholson (clare.nicholson@stmarys.ac.uk): Faculty of Sports, Health and Applied Science, St Mary's University, Twickenham, Waldegrave Road, Twickenham, London TW1 $4 S X$ 


\section{References}

Altermark, N. (2017). "The Post-Institutional Era: Visions of History in Research on Intellectual

Disability." Disability \& Society 32(9): 1315-1332.

American Psychiatric Association. (2013). Diagnostic and statistical manual of mental disorders

(5th ed.). Arlington : American Psychiatric Publishing.

Antaki, C., Finlay, W. M. L., \& Walton, C. (2009). Choices for people with intellectual disabilities:

Official discourse and everyday practice. Journal of Policy and Practice in Intellectual

Disabilities, 6(4), 260-266.

Björne, P. (2020). As if living like others: An idealisation of life in group homes for people with intellectual disability. Journal of Intellectual \& Developmental Disability, 1-7.

Costello, B. A., \& Roberts, F. (2001). Medical recommendations as joint social practice. Health Communication, 13(3), 241-260.

Department of Health. (2001). Valuing people A new strategy for learning disability for the 21st century: A white paper London: The Stationery Office.

Department of Health (2005). Mental Capacity Act. London, HMSO.

Department of Health (2007) Mental Capacity Act Code of Practice. London. HMSO

Department of Health. (2009a). Our Health, Our Care, Our Say. London: The Stationery Office.

Department of Health. (2009b). Valuing people now: A new three-year strategy for people with learning disabilities. London: The Stationery Office. 
Department of Health (2015) No Voice Unheard, No Right Ignored. London: The Stationery Office.

Finlay, W. M. L., Antaki, C., \& Walton, C. (2008b). Saying no to the staff: an analysis of refusals in a home for people with severe communication difficulties. Sociology of health \& illness, $30(1), 55-75$.

Finlay, W. M. L., Antaki, C., \& Walton, C. (2008c). A manifesto for the use of video in service improvement and staff development in residential services for people with learning disabilities. British Journal of Learning Disabilities, 36 (4)

Finlay, W. M., Antaki, C., Walton, C., \& Stribling, P. (2008a). The dilemma for staff in 'playing a game' with a person with profound intellectual disabilities: Empowerment, inclusion and competence in interactional practice. Sociology of Health \& Illness, 30(4), 531-549.

Finlay, W. M., Walton, C., \& Antaki, C. (2008). Promoting choice and control in residential services for people with learning disabilities. Disability \& society, 23(4), 349-360.

Forrester, M., \& Ramsden, C.A (2000) Discursive ethnomethodology: Analysing power and resistance in talk, Psychology, Crime \& Law, 6(4), 281-304

Goodwin, C., (1981) Conversational organization: Interaction between speakers and hearers. New York: Academic Press

Heath, C. (1986). Body movement and speech in medical interaction. Cambridge: Cambridge University Press.

Hellzen, O., Haugenes, M., \& Østby, M. (2018). 'It's my home and your work': the views of a filmed vignette describing a challenging everyday situation from the perspective of people 
with intellectual disabilities. International journal of qualitative studies on health and wellbeing, 13(1), 1468198.

Heritage, J. (2003) Designing questions and setting agendas in the news interview. In P. Glenn, C Lebaron \& J.Mandelbaum (Eds.) Studies in language and social interaction (pp. 57-90). Mahwah, New Jersey: Lawrence Erlbaum.

Hoey, E.M., (2017) Sequence recompletion: A practice for managing lapses in conversation Journal of Pragmatics, 7, 47-63

Jackson, C., Land, V., \& Holmes, E. J. (2017). Healthcare professionals' assertions and women's responses during labour: A conversation analytic study of data from One born every minute. Patient education and counselling, 100(3), 465-472.

Jingree, T., Finlay, W. M. L., \& Antaki, C. (2006). Empowering words, disempowering actions: an analysis of interactions between staff members and people with learning disabilities in residents' meetings. Journal of Intellectual Disability Research, 50(3), 212-226.

Joyce, J. (2017). Guest Blog: Jack Joyce on Loughborough's “Resistance Day. Available: https://rolsi.net/guest-blogs/guest-blog-jack-joyce-on-loughboroughs-resistance-day/. Last accessed 27th April 2020.

Kent, A. (2011). Directing dinnertime: Practices and resources used by parents and children to deliver and respond to directive actions (Doctoral dissertation). Retrieved from https://dspace.lboro.ac.uk/2134/8960 
Kent, A. (2012). Compliance, resistance and incipient compliance when responding to directives. Discourse Studies, 14(6), 711-730.

Kidwell, M. (2006) 'Calm down!' the role of gaze in the interactional management of hysteria by the police. Discourse Studies, 8(6), 745-770.

Kidwell, M., (2009). Gaze shift as an interactional resource for very young children. Discourse processes, 46(2-3), 145-160.

Kitzinger, C. (2000). How to resist an idiom. Research on language and social interaction, 33(2), 121-154.

Lytra, V. (2007) Teasing in contract encounters: Frames, participant positions and responses. Multilingual-Journal of Cross-Cultural and Interlanguage Communication, 26(4), 381-408.

MacMartin, C., (2008) Resisting optimistic questions in narrative and solution-focused therapies. In A Perakyla, C.antaki, S.Vehvilhainen \& I. Leudar (Eds.) Conversation analysis and psychotherapy (pp 89-90)

Mandelbaum, J. (1991). Conversational non-cooperation: An exploration of disattended complaints. Research on Language \& Social Interaction, 25(1-4), 97-138.

Monzoni, C. M., Duncan, R., Grünewald, R., \& Reuber, M. (2011). Are there interactional reasons why doctors may find it hard to tell patients that their physical symptoms may have 
emotional causes? A conversation analytic study in neurology outpatients. Patient education and counseling, 85(3), 189-200.

Muntigl, P. (2013). Resistance in couples counselling: Sequences of talk that disrupt progressivity and promote disaffiliation. Journal of Pragmatics, 49(1), 18-37.

Nicholson, C. (2017). Misalignment between the DSM-5 and the Mental Capacity Act. Available: https://blogs.bmj.com/bmj/2017/03/07/clare-nicholson-misalignment-between-the-dsm-5and-the-mental-capacity-act/. Last accessed 20th November 2018.

Nind, M., \& Hewett, D. (2001). A practical guide to intensive interaction Worcestershire: British Institute of Learning Disabilities.

Nind, M., \& Hewett, D. (2012). Access to communication: Developing the basics of communication with people with severe learning difficulties through intensive interaction London: Routledge.

Porter, J., Ouvry, C., Morgan, M., \& Downs, C. (2001). Interpreting the communication of people with profound and multiple learning difficulties. British Journal of Learning Disabilities, 29(1), 12-16.

Roberts, F. (1999) Talking about treatment: Recommendations for breast cancer adjuvant therapy. New York: Oxford University Press.

Sidnell, J., \& Stivers, T., (2014). A Handbook of Conversation Analysis, London: Wiley-Blackwell 
Stivers, T. (2006) Treatment decisions: Negotiations between doctors and parents in acute care encounters. In Communication in medical care: Interaction between primary care physicians and patients (pp. 279-312). Cambridge University Press.

Stivers, T. (2007). Alternative recognitionals in person reference. In Person reference in interaction: Linguistic, cultural, and social perspectives (pp. 73-96). Cambridge University Press.

Svanelöv, E. (2019) An observation study of power practices and participation in group homes for people with intellectual disability, Disability \& Society, 35:9, 14191440, DOI: $\underline{10.1080 / 09687599.2019 .1691978}$

United Nations. (2006). Guiding Principles of the Convention. Available: https://www.un.org/development/desa/disabilities/convention-on-the-rights-of-persons-withdisabilities/guiding-principles-of-the-convention.html. Last accessed 22nd Oct 2020.

Vehvilhainen, S. (2008) Identifying and managing resistance in psychoanalytic interaction. In A. Perakyla, C. antaki, S. Vehvlainen \& I.Leudar (Eds.) Conversation analysis and psychotherapy (pp. 123-138). Cambridge: Cambridge University Press

Ware, J. E. (2003). Conceptualization and measurement of health-related quality of life: Archives of physical medical and Rehabilitation 84(2) pp43-51

Wehmeyer, M. L., \& Field, S. L. (2007). Self-determination: Instructional and assessment strategies. London: Sage. 


\section{Appendix A: Compatibility Mode}

Simplified Notes of Jeffersonian CA Transcription System taken from the University of California Website (accessed 2020). Available at: http://pages.ucsd.edu/ johnson/COGS102B/

Jeffersonian Transcription Notation includes the following symbols:

\begin{tabular}{|c|c|c|}
\hline Symbol & Name & Use \\
\hline [ text ] & Brackets & Indicates the start and end points of overlapping speech. \\
\hline$=$ & Equal Sign & $\begin{array}{l}\text { Indicates the break and subsequent continuation of a single } \\
\text { interrupted utterance. }\end{array}$ \\
\hline (\# of seconds) & Timed Pause & $\begin{array}{l}\text { A number in parentheses indicates the time, in seconds, of a } \\
\text { pause in speech. }\end{array}$ \\
\hline (.) & Micropause & A brief pause, usually less than 0.2 seconds. \\
\hline . or $\downarrow$ & $\begin{array}{l}\text { Period or Down } \\
\text { Arrow }\end{array}$ & Indicates falling pitch. \\
\hline ? or $\uparrow$ & $\begin{array}{l}\text { Question Mark or } \\
\text { Up Arrow }\end{array}$ & Indicates rising pitch. \\
\hline , & Comma & Indicates a temporary rise or fall in intonation. \\
\hline- & Hyphen & Indicates an abrupt halt or interruption in utterance. \\
\hline$>$ text $<$ & $\begin{array}{l}\text { Greater than / Less } \\
\text { than symbols }\end{array}$ & $\begin{array}{l}\text { Indicates that the enclosed speech was delivered more rapidly } \\
\text { than usual for the speaker. }\end{array}$ \\
\hline$<$ text $>$ & $\begin{array}{l}\text { Less than / Greater } \\
\text { than symbols }\end{array}$ & $\begin{array}{l}\text { Indicates that the enclosed speech was delivered more slowly } \\
\text { than usual for the speaker. }\end{array}$ \\
\hline$\circ$ & Degree symbol & Indicates whisper or reduced volume speech. \\
\hline ALL CAPS & Capitalized text & Indicates shouted or increased volume speech. \\
\hline underline & Underlined text & Indicates the speaker is emphasizing or stressing the speech. \\
\hline$:::$ & Colon(s) & Indicates prolongation of an utterance. \\
\hline (hhh) & & Audible exhalation \\
\hline ? or (.hhh) & High Dot & Audible inhalation \\
\hline ( text ) & Parentheses & Speech which is unclear or in doubt in the transcript. \\
\hline$(($ italic text $))$ & Double Parentheses & Annotation of non-verbal activity. \\
\hline
\end{tabular}

Jeffersonian Transcription Notation is described in G. Jefferson, "Transcription Notation," in J. Atkinson and J. Heritage (eds), Structures of Social Interaction, New York: Cambridge University Press, 1984. 